\title{
ANALISIS PENAWARAN IKAN PATIN (Pangasius sp) DI KOTA PALEMBANG
}

\author{
Analysis Of Patin Fish Supply in Palembang City \\ Lia Perwita Sari ${ }^{1)}$ dan Yulia Puspita Sari ${ }^{2)}$ \\ ${ }^{1)}$ Budidaya Perikanan Fakultas Perikanan Universitas PGRI Palembang \\ 2) Budidaya Perikanan Fakultas Perikanan Universitas PGRI Palembang \\ Jl. Ahmad Yani Lrg. Gotong Royong 9/10 Ulu Palembang \\ Hp. +6285267763027 \\ Email : lehakps@yahoo.co.id
}

\begin{abstract}
Abstrak
Peningkatan konsumsi terhadap ikan Patin diharapkan dapat membuka peluang baik bagi petani dan pedagang agar memacu produksi ikan Patin untuk memenuhi permintaan pasar baik lokal maupun standar ekspor. Peningkatan konsumsi ikan Patin akan mendorong peningkatan penawaran di tingkat petani maupun pedagang. Tingkat penawaran berhubungan dengan jumlah produksi yang mampu disediakan produsen untuk memenuhi permintaan pasar.Tujuan dari penelitian ini untuk menganalisis penawaran ikan Patin di Kota Palembang. Metode penelitian menggunakan metode survei. Lokasi penelitian ditentukan secara sengaja (purposive) yaitu di Kota Palembang, yaitu di Pasar Alang-alang Lebar, Pasar KM 5, Pasar Cinde, Pasar Kuto, Pasar Soak Bato, Pasar Jakabaring, Pasar Kertapati dan Pasar Satelit Multi Wahana. Penarikan sampel penelitian dilakukan dengan menggunakan metode accidental sampling (kebetulan). Pengambilan responden melalui metode ini adalah konsumen yang sedang menjual ikan Patin yang dijumpai di pasar tradisional untuk meminta pendapat mereka mengenai hal yang dibutuhkan untuk kelancaran penelitian ini sebanyak 40 orang. Hasil penelitian menyatakan bahwa penawaran ikan patin secara serempak dipengaruhi oleh harga beli pedagang, biaya penjualan, dan keuntungan. Secara parsial, hanya variabel biaya penjualan yang berpengaruh nyata terhadap penawaran ikan Patin.
\end{abstract}

Kata Kunci: Penawaran, ikan patin, biaya penjualan, keuntungan

\begin{abstract}
The increase in consumption of Patin fish is expected to open opportunities for farmers and traders to encourage Patin fish production to meet market demand both locally and export standards. Increased consumption of Patin fish will encourage increased supply at the level of farmers and traders. The level of supply relates to the amount of production that producers can provide to meet market demand. The purpose of this study was to analyze the supply of Patin fish in the city of Palembang. The research method uses the survey method. The research locations were determined purposively in Palembang City, namely in Alang-alang Lebar Market, KM 5 Market, Cinde Market, Kuto Market, Bato Soak Market, Jakabaring Market, Pasar Kertapati and Multi Wahana Satellite Market. The withdrawal of research samples is done using the accidental sampling method. Taking respondents through this method are consumers who are selling Patin fish found in traditional markets to ask their opinions about the things needed for the smooth running of this study as many as 40 people. The results of the study state that catfish offerings are simultaneously influenced by merchant purchase prices, sales costs, and profits. Partially, only the sales cost variable has a significant effect on Patin fish supply.
\end{abstract}

Keywords: fish supply, Patin fish, cost of sales, profit 


\section{PENDAHULUAN}

Peningkatan konsumsi ikan Patin akan mendorong peningkatan penawaran di tingkat petani maupun pedagang. Tingkat penawaran berhubungan dengan jumlah produksi yang mampu disediakan produsen untuk memenuhi permintaan pasar.Faktor stok ikan yang sulit di pasaran kadang menjadi kendala dalam pemenuhan permintaan pasar.Selain itu kualitas ikan dari segi mutu, ukuran dan warna mengalami penurunan dan tidak seragam (Abdusysyahid, 2006). Fluktuasi harga ikan hasil panen juga mempengaruhi ketersediaan ikan Patin.Harga ikan Patin cenderung mengalami kenaikan setiap tahun yang dipengaruhi oleh biaya produksi (Lukas, 2012).Produksi ikan Patin di Sumatera Selatan berada pada posisi tertinggi yaitu sebesar 231.258 ton/th di antara budidaya ikan air tawar lainnya.

Tabel 1. Produksi Ikan Air Tawar di Sumatera Selatan Tahun 2014 (Ton/th)

\begin{tabular}{clc}
\hline \multirow{2}{*}{ No. } & Komoditi & Total Produksi Ikan (Ton/th) \\
\cline { 3 - 3 } & & $\mathbf{2 0 1 4}$ \\
\hline 1. & Patin & $231.258,0$ \\
2. & Nila & $140.561,0$ \\
3. & Lele & $37.818,0$ \\
4. & Bandeng & $7.084,8$ \\
5. & Mas & $5.573,0$ \\
\hline
\end{tabular}

Sumber : Dinas Kelautan dan Perikanan Sumatera Selatan, 2015

Jumlah produksi ikan Patin yang dihasilkan

akan mempengaruhi jumlah penawaran. Sedangkan jumlah penawaran akan mempengaruhi harga. Harga yang rendah terjadi pada saat produksi sedang melimpah dan sebaliknya pada saat produksi sedikit maka harga tinggi sehingga mempengaruhi pendapatan petani ikan Patin. Penawaran konsumen akan ikan Patin diantaranya dipengaruhi oleh harga ikan Patin, harga ikan lainnya, jumlah produksi, dan biaya produksi.

Kenaikan jumlah penawaran yang dilakukan produsen berhubungan dengan meningkatnya permintaan konsumen terhadap ikan patin itu sendiri.Selain karena tuntutan permintaan pasar, keuntungan yang diperoleh produsen sangat menentukan semangatnya dalam bekerja untuk lebih meningkatkan penawarannya terhadap ikan patin. Melihat fenomena tersebut penulis tertarik untuk melakukan penelitian dengan judul: ANALISIS PENAWARAN IKAN PATIN (Pangasius sp) DI KOTA PALEMBANG. Adapun yang menjadi tujuan penelitian ini adalah untuk menganalisis faktor-faktor yang mempengaruhi penawaran ikan patin di Kota Palembang

\section{METODE PENELITIAN}

\section{Waktu dan Tempat}

Penelitian Lokasi penelitian adalah delapan pasar tradisional di Kota Palembang yaitudi Pasar Alang-alang Lebar, Pasar KM 5, Pasar Cinde, Pasar Kuto, Pasar Soak Bato, Pasar Jakabaring, Pasar Kertapati dan Pasar Satelit Multi Wahana. yang dilakukan pada bulan Juli 2018. Alasan penentuan lokasi penelitian karena delapan pasar ini adalah pasar terbesar di Kota Palembang.

\section{Metode Penelitian}

Penarikan sampel penelitian dilakukan dengan menggunakan metode accidental sampling (kebetulan). Pengambilan responden melalui metode ini adalah penjual yang sedang menjual ikan Patin yang dijumpai di daerah penelitian untuk meminta pendapat mereka mengenai hal yang dibutuhkan untuk kelancaran penelitian ini.Besarsampel responden penjual ikan Patin ditetapkan 40 orang, masing-masing 5 orang di setiap pasar.

\section{Jenis dan Sumber Data}

Jenis data yang digunakan dalam penelitian ini adalah data primer dan data sekunder.Data primer diperoleh dari wawancara langsung responden dengan mempergunakan pertanyaan/kuesioner yang telah dipersiapkan.Data primer yang dikumpulkan meliputi tingkat penawaran ikan patin. Sedangkan data sekunder adalah data yang didapat dari publikasi instansi terkait atau lembaga yang berhubungan dengan penelitian ini.Sumber data penelitian ini adalah dari Badan Pusat Statistik Provinsi Sumatera Selatan dan Dinas Kelautan dan Perikanan Provinsi Sumatera Selatan.

Metode Pengolahan Data dan Analisis Data

Untuk mengetahui faktor-faktor yang mempengaruhi penawaran ikan Patin di Kota Palembang dibutuhkan data antara lain :harga beli pedagang, biaya penjualan dan keuntungan . Secara matematis, penawaran ikan Patin dirumuskan sebagai berikut :

Dimana :

$\mathrm{b}_{\mathrm{o}} \quad=$ Konstanta

$\mathrm{Y} \quad=$ Jumlah penawaran ikan Patin (kg/bulan)

$\mathrm{X}_{1} \quad=$ Harga ikan Patin $(\mathrm{Rp} / \mathrm{kg})$

$\mathrm{X}_{2} \quad=$ Biaya Penjualan $(\mathrm{Rp} / \mathrm{bln})$

$\mathrm{X}_{3} \quad=$ Keuntungan $(\mathrm{Rp} / \mathrm{kg} / \mathrm{bulan})$

$\mathrm{b}_{1}-\mathrm{b}_{3}=$ Koefisien regresi

$\mathrm{e} \quad=$ error

Hasil perhitungan dari analisis regresi linier berganda di atas, perlu dilakukan pengujian model agar tidak menghasilkan persamaan yang bias. Uji statistik yang dimaksud meliputi uji $\mathrm{R}^{2}$, uji $\mathrm{F}$ dan uji t 


\section{HASIL DAN PEMBAHASAN}

\section{A. Faktor-faktor yang Mempengaruhi Penawaran Ikan Patin di Kota Palembang}

Dari hasil penelitian mengenai penawaran ikan patin yang dilakukan oleh peneliti di beberapa pasar tradisional Kota Palembang diperoleh :

\section{Harga Beli Pedagang $\left(\mathbf{X}_{1}\right)$.}

Harga beli ikan patin yang dibeli oleh pedagang bervariasi. Dari data yang diperoleh bahwa harga rata-rata ikan patin yang dibeli pedagang adalah sebesar Rp. 18.725/kg, harga beli pedagang tertinggi sebesar Rp. $20.000 / \mathrm{kg}$, dan harga beli pedagang terendah sebesar Rp. 17.000/kg.

\section{Biaya Penjualan $\left(\mathbf{X}_{2}\right)$}

Biaya penjualan rata-rata ikan patin adalah sebesar Rp 3.404.875/bulan, biaya penjualan pedagang tertinggi sebesar Rp. 10.700.000/bulan, dan biaya penjualan pedagang terendah sebesar Rp. 750.000/bulan.

\section{Keuntungan $\left(\mathbf{X}_{3}\right)$}

Keuntungan yang diperoleh pedangang ikan patin bervariasi. Data yang diperoleh di lapangan, bahwa keuntungan rata-rata ikan patin adalah sebesar Rp 6.340.000/bulan, keuntungan pedagang tertinggi sebesar Rp. 12.000.000/bulan, dan keuntungan pedagang terendah sebesar Rp. 600.000/bulan.

Dari hasil penelitian terhadap 40 orang responden pedagang ikan patin telah ditetapkan beberapa faktor yang mempengaruhi penawaran ikan patin di Kota Palembang yaitu harga beli pedagang $\left(\mathrm{X}_{1}\right)$, biaya penjualan $\left(\mathrm{X}_{2}\right)$, dan keuntungan $\left(\mathrm{X}_{3}\right)$. Dari variabel independen (variabel bebas) tersebut akan dilihat seberapa besar pengaruhnya terhadap jumlah penawaran ikan patin (Y) sebagai variabel dependen (variabel terikat). Untuk mengetahui adanya pengaruh faktor-faktor tersebut terhadap penawaran ikan patin digunakan analisis Regresi Linier Berganda. Adapun persamaan yang diperoleh dari hasil analisis adalah :

$$
\mathrm{Y}=6,610-0,290 \mathrm{X}_{1}+0,302 \mathrm{X}_{2}+0,090 \mathrm{X}_{3}+\mathrm{e}
$$

Dimana :

$\mathrm{b}_{\mathrm{o}}=$ Konstanta

$\mathrm{Y}=$ Jumlah penawaran ikan Patin $(\mathrm{kg} / \mathrm{bulan})$

$\mathrm{X}_{1}=$ Harga Beli Pedagang $(\mathrm{Rp} / \mathrm{kg})$

$\mathrm{X}_{2}=$ Biaya Penjualan $(\mathrm{Rp} / \mathrm{bln})$

$\mathrm{X}_{3}=$ Keuntungan $(\mathrm{Rp} / \mathrm{kg} / \mathrm{bulan})$

$\mathrm{b}_{1}-\mathrm{b}_{3}=$ Koefisien regresi

$\mathrm{e}=$ error

Tabel 2. Hasil Analisis Regresi Faktor-Faktor yang Mempengaruhi Penawaran Ikan Patin di Kota Palembang

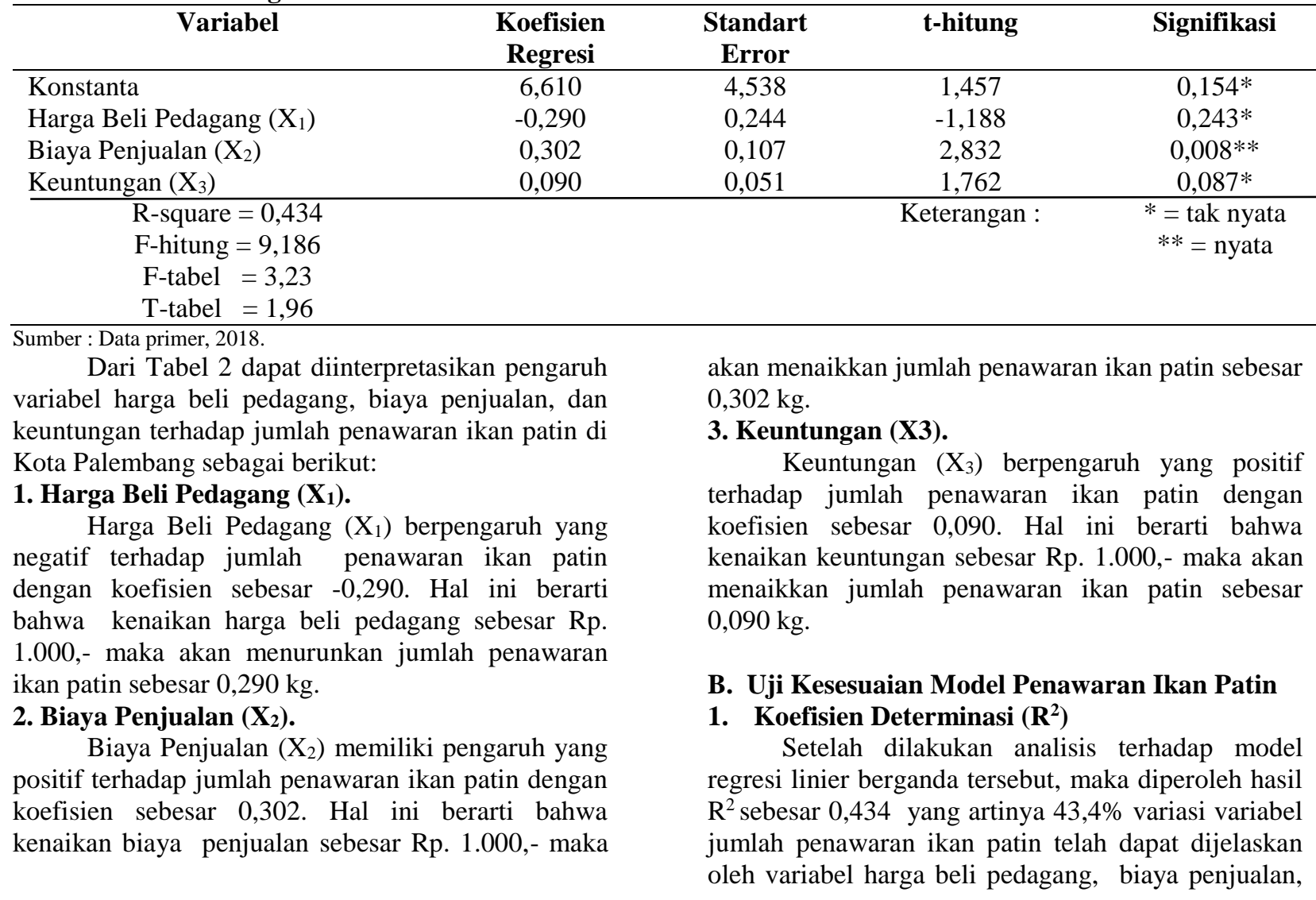


dan keuntungan. Sisanya sebesar 56,6\% dijelaskan oleh variabel lain di luar model.

\section{Uji $F$}

Berdasarkan Tabel ANOVA dapat dilihat bahwa secara serempak variabel harga beli, biaya penjualan, dan keuntungan ternyata signifikan secara statistik pada $\propto=5 \%$. Hal ini dapat dilihat dari uji $\mathrm{F}$, dimana F-hitung $(9,186)>$ F-tabel $(3,23)$, sehingga dapat disimpulkan bahwa variabel harga beli pedagang, biaya penjualan, dan keuntungan berpengaruh nyata terhadap variabel jumlah penawaran ikan patin.

\section{Uji t}

Untuk menguji apakah variabel bebas secara parsial berpengaruh atau tidak terhadap variabel terikat, maka dilakukan uji t, jika t-hitung > t-tabel, maka Ho ditolak, sedangkan jika t-hitung < t-tabel, maka Ho diterima.Jika tingkat signifikansi $<0.05$, maka Ho ditolak dan tingkat signifikansi >0.05, maka Ho diterima.

\section{a. Harga Beli $\left(\mathbf{X}_{1}\right)$.}

Secara parsial, variabel harga beli pedagang tidak berpengaruh secara nyata terhadap jumlah penawaran ikan patin yaitu pada taraf kepercayaan 95\%. Dimana t-hitung $(-1,188)<$ t-tabel $(1,96)$ dan tingkat signifikansi 0,243>0,05.

\section{b. Biaya Penjualan ( $\left.\mathbf{X}_{2}\right)$.}

Secara parsial, variabel biaya penjualan berpengaruh secara nyata terhadap jumlah penawaran ikan patin yaitu pada taraf kepercayaan 95\%. Dimana t-hitung $(2,832)>$ t-tabel $(1,96)$, dan tingkat signifikansi $0,008<0,05$.

\section{c. Keuntungan $\left(\mathrm{X}_{3}\right)$.}

Secara parsial, variabel keuntungan tidak berpengaruh secara nyata terhadap jumlah penawaran ikan patin yaitu pada taraf kepercayaan 95\%. Dimana t-hitung $(1,762)<$ t-tabel $(1,96)$, dan tingkat signifikansi $0,087>0,05$.

\section{KESIMPULAN DAN SARAN}

\section{A. Kesimpulan}

Bedasarkan hasil penelitian yang dilakukan maka dapat ditarik kesimpulan bahwa penawaran ikan patin secara serempak dipengaruhi oleh harga beli pedagang, biaya penjualan, dan keuntungan. Hal ini dapat dilihat dari uji F, dimana Fhitung $(9,186)>$ FTabel $(3,23)$ pada $\propto=5 \%$. Secara parsial, variabel harga beli pedagang tidak berpengaruh secara nyata terhadap jumlah penawaran ikan patin yaitu pada taraf kepercayaan 95\%. Dimana dapat t-hitung $(-1,188)<$ t-tabel $(1,96)$. Secara parsial, variabel biaya penjualan berpengaruh secara nyata terhadap jumlah penawaran ikan patin yaitu pada taraf kepercayaan 95\%. Dimana dapat dilihat bahwa t-hitung $(2,832)>\mathrm{t}$-tabel $(1,96)$. Secara parsial, variabel keuntungan tidak berpengaruh secara nyata terhadap jumlah penawaran ikan patin yaitu pada taraf kepercayaan 95\%. Dimana dapat dilihat bahwa t-hitung $(1,762)<\mathrm{t}$-tabel $(1,96)$.

\section{B. Saran}

Berdasarkan hasil penelitian mengenai faktorfaktor yang mempengaruhi penawaran ikan patin di Kota Palembang, maka saran yang dapat diberikan bagi penelitian selanjutnya disarankan sebaiknya peneliti membahas mengenai strategi peningkatan pemasaran ikan patin, komoditi yang berperan di Kota Palembang.

\section{UCAPAN TERIMA KASIH}

Pada kesempatan ini penulis mengucapkan terima kasih yang sebesar-besarnya kepada Kemeristekdikti Republik Indonesia, L2Dikti Wilayah II, PD. Pasar Jaya Palembang dan Universitas PGRI Palembang yang telah memberikan kesempatan dan banyak membantu penulis dalam melakukan penelitian ini.

\section{DAFTAR PUSTAKA}

Abdudydyahid, Said. 2006. Analisa Fluktuasi Permintaan Ikan Laut Pada Beberapa Rumah Makan Di Kota Samarinda. Jurnal Ekonomi Pertanian dan Pembangunan. 3 (1) : 36-43.

Badan Pusat Statistik Sumatera Selatan. 2015. Sumatera Selatan Dalam Angka 2015. BPS Provinsi Sumatera Selatan. Sumatera Selatan.

Dinas Kelautan dan Perikanan Provinsi Sumatera Selatan.2015. Statistik Perikanan Budidaya. Sumatera Selatan.

Lukas. 2012. Analisis Biaya Produksi dan Pendapatan Budidaya Ikan Patin (Pangasius pangasius) di Kabupaten Kapuas.Jurnal Hewani Tropika. 1 (1) : 36-39. 